\title{
Editorial for the special issue on "Modelling, simulation, and optimization in health care"
}

\author{
Paola Cappanera ${ }^{1}$ - Jingshan $\mathrm{Li}^{2}$ - Evren Sahin ${ }^{3} \cdot$ Nico J. Vandaele ${ }^{4}$. \\ Filippo Visintin ${ }^{5}$
}

Published online: 7 February 2020

(c) Springer Science+Business Media, LLC, part of Springer Nature 2020

In a world characterized by an ever-increasing demand for health services and by dramatic pressures to reduce health spending, scholars in the Operations Management (OM)/Operations Research (OR) fields are called upon to develop new models, methods and approaches to support the design, analysis, and improvement of effective health care delivery systems.

Developing these models, however, is a very challenging task. Health care delivery systems, in fact, are inherently complex, as they involve a plurality of stakeholders with conflicting goals and priorities, operating in contexts affected by high variability and-more often than not-limited resources.

This special issue of the Flexible Services and Manufacturing (FSM) Journal presents eight papers making a substantial contribution to the OM/OR theory while at the same time successfully addressing common practical problems arising from real-life health care settings.

Filippo Visintin

filippo.visintin@unifi.it

Paola Cappanera

paola.cappanera@unifi.it

Jingshan Li

jingshan.li@wisc.edu

Evren Sahin

evren.sahin@centralesupelec.fr

Nico J. Vandaele

nico.vandaele@kuleuven.be

1 Dipartimento di Ingegneria dell'Informazione, University of Florence, Florence, Italy

2 Department of Industrial and Systems Engineering, University of Wisconsin-Madison, Madison, USA

3 CentraleSupélec, Laboratoire Génie Industriel, Paris, France

4 Katholieke Universiteit Leuven, Louvain, Belgium

5 Dipartimento di Ingegneria Industriale, University of Florence, Florence, Italy 
Some of the papers included in this special issue are extended versions of the papers presented at the Third Health Care System Engineering Conference (HCSE) that was held in Florence, Italy, in May 2017. There were 34 submissions for this special issue. After a thorough peer-review according to the standards of the FSM journal, the following eighth papers were accepted for publication.

Duma and Aringhieri (2020) propose a framework to mine patterns in a sequence of activities, i.e., paths, occurring when patients, with different characteristics and urgency, access Emergency Departments (ED). The study presents an ad hoc process mining model capable to replicate a large variety of paths and to predict the use of the ED resources by each patient based on the information known upon patient access. The framework is tested on real data coming from the Ospedale Sant'Antonio Abate (Cantù, Italy).

Zeng et al. (2020) introduce a network model to support the design and improvement of rapid response systems for multiple acute patients with declining clinical conditions. The study presents also iterative methods to evaluate the mean decision time, i.e., the average time from the detection of a patient's declining condition to a physician's treatment decision being made. These methods lead to convergent results and high accuracy in performance evaluation.

Kuo et al. (2020) propose a framework to address the trade-off between schedule efficiency and accessibility to service in appointment scheduling with overbooking. The framework consists of a stochastic mixed-integer linear program to determine an optimal appointment schedule within a session and is used in combination with a simulation model for guiding the scheduling decisions in the long run. Such an approach thus makes it possible to evaluate both the within-thesession and longer-term schedule performance. Computational experiments are based on actual data collected from a medical imaging center of a hospital.

Guido et al. (2020) propose a novel optimization model to address an outpatient appointment scheduling problem. The model aims at maximizing the number of appointments, at reducing patient waiting time, and at increasing patient satisfaction. The proposed combinatorial problem is solved by a logic formalism, widely used in the artificial intelligence literature. In addition, the authors propose a three-phase approach to increase computational efficiency. Computational results are based on real data from the Rheumatology Department of the Careggi University Hospital (Florence, Italy) as well as on realistic instances purposely generated.

Garaix et al. (2020) address a daily appointment scheduling problem with random deferral for chemotherapy outpatients. The authors propose a heuristic approach to determine the order in which patients will be treated in an ambulatory chemotherapy center. Each patient is assumed to follow a personalized treatment plan that fixes dates for a series of drug injections separated by recovery periods. In addition, they introduce a GRASP algorithm that allows rescheduling patients in case a drug injection is canceled due to weak patient conditions. Benchmark data sets are built based on historical data of the French chemotherapy facility, ICL in Saint-Etienne.

$\mathrm{Li}$ et al. (2020) model a radiotherapy treatment process as a queueing system with multiple queues and develop a new class of scheduling policies that are simple, flexible and fair to patients. They also propose an adaptive policy that is efficient to 
deal with unknown and fluctuating arrival rates. The parameters of the policies are selected resorting to simulation-based optimization heuristics.

Kraul (2020) presents a tactical model that supports the construction of annual schedules to train anesthesiology medicine residents. Specifically, residents need to perform different interventions several times to become specialists. The task-related problem is formulated in two stages considering the total number of interventions, equal progress in training as well as continuity of care. The second stage of their formulation results in a quadratic program and the authors develop a genetic algorithm using standard crossovers which is able to construct annual schedules for an existing stock of residents. The algorithm is tested by comparing the solutions of the genetic algorithm and standard software with a real-world situation of a German training hospital.

Wang et al. (2020) propose a combined approach for conducting cost-effectiveness analysis aiming at supporting medical decisions. Specifically, a Markov model is proposed to represent patients' health state transitions, and two hybrid metaheuristics estimate the transition probabilities. Based on the estimated transition probabilities, the cost-effectiveness analysis proposed is conducted to compare different medical interventions. The model has been applied to a case study concerned with the comparison of two immunosuppressants to treat patients subject to renal transplantation.

\section{References}

Duma D, Aringhieri R (2020) An ad hoc process mining approach to discover patient paths of an Emergency Department. Flex Serv Manuf J. https://doi.org/10.1007/s10696-018-9330-1

Garaix T, Rostami S, Xie X (2020) Daily outpatient chemotherapy appointment scheduling with random deferral. Flex Serv Manuf J. https://doi.org/10.1007/s10696-018-9326-X

Guido R, Ielpa G, Conforti D (2020) Scheduling outpatient day service operations for rheumatology diseases. Flex Serv Manuf J. https://doi.org/10.1007/s10696-019-09354-7

Kraul S (2020) Annual scheduling for anesthesiology medicine residents in task-related programs with a focus on continuity of care. Flex Serv Manuf J. https://doi.org/10.1007/s10696-019-09365-4

Kuo Y-H, Balasubramanian H, Chen Y (2020) Medical appointment overbooking and optimal scheduling tradeoffs between schedule efficiency and accessibility to service. Flex Serv Manuf J. https://doi. org/10.1007/s10696-019-09340-z

Li S, Koole G, Xie X (2020) An adaptive priority policy for radiotherapy scheduling. Flex Serv Manuf J. https://doi.org/10.1007/s10696-019-09373-4

Wang X, Geng N, Qiu J, Jiang Z, Zhou L (2020) Markov model and meta-heuristics combined method for cost-effectiveness analysis. Flex Serv Manuf J. https://doi.org/10.1007/s10696-019-09369-0

Zeng Z, Fan Z, Xie X, Swartz CH, De Priest P, Li J (2020) A two-level iteration approach for modeling and analysis of rapid response process with multiple deteriorating patients. Flex Serv Manuf J. https://doi. org/10.1007/s10696-019-09347-6

Publisher's Note Springer Nature remains neutral with regard to jurisdictional claims in published maps and institutional affiliations.

Paola Cappanera is an Associate Professor of Operations Research at the Department of Information Engineering of the University of Florence. She has a multidisciplinary education background and 
she defended her PhD thesis in 2000 (University of Milan). Her main research interest is in combinatorial optimisation with particular attention to healthcare, telecommunications, and transportation. She investigated several research topics stemming from very different real contexts; the unifying feature in most of her papers is the focus on network flow-based methodologies and on problem structure. She is author of research papers published in prestigious international journals such as Computers and Operations Research, Computer Communications, Computer Networks, Discrete Applied Mathematics, Flexible Services and Manufacturing Journal, IEEE Transactions on Neural Networks and Learning Systems, IMA Journal of Management Mathematics, Informs Journal on Computing, International Journal of Production Economics, Networks, Omega, Operations Research, Operations Research for Health Care, and Transportation Science. She is currently in the Editorial Board of Flexible Services and Manufacturing Journal, and Operations Research for Health Care.

Jingshan Li received the B.S. degree from Tsinghua University, Beijing, China, the M.S. degree from Chinese Academy of Sciences, Beijing, and the Ph.D. degree from University of Michigan, Ann Arbor, in 1989, 1992, and 2000, respectively. He was a Staff Research Engineer at General Motors Research and Development Center from 2000 to 2006, and was with University of Kentucky from 2006 to 2010. He is now a Professor in Department of Industrial and Systems Engineering, University of Wisconsin-Madison. His primary research interests are in modeling, analysis and control of manufacturing and healthcare systems. He has published a textbook, 7 book volumes, and over 200 refereed journal articles and conference proceedings. He is an IEEE Fellow and an IEEE Distinguished Lecturer in robotics and automation. He received 2010 NSF Career Award, 2009 IIE Transactions Best Application Paper Award, 2005 IEEE Transactions on Automation Science and Engineering Best Paper Award, 2006 IEEE Early Industry/Government Career Award in Robotics and Automation, and multiple awards in flagship international conferences. He is a Senior Editor of IEEE Transactions on Automation Science and Engineering and IEEE Robotics and Automation Letters, Department Editor of IIE Transactions, Area Editor of Flexible Service and Manufacturing Journal, and Associate Editor of International Journal of Production Research and International Journal of Automation Technology. He was the Program Chair of 2019 IEEE International Conference on Automation Science and Engineering and was the General and Program Co-Chair in 2013 and 2015. He was the founding Chair of IEEE Technical Committee on Sustainable Production Automation (2012-2016) and has been the Chair of the Technical Committee on Automation for Healthcare Management since 2016.

Evren Sahin is Professor of Operations Management at CentraleSupelec (Ecole Centrale Paris, before 2015). She received a Ph.D. (2004) in Industrial Engineering from Ecole Centrale Paris. Her research interests are agility in supply chains, sustainable supply chains and circular economy, and healthcare systems engineering \& operations management. Evren SAHIN has conducted research for a number of industrial companies: Renault, Sanofi, Safran, Air Liquide, L'Oréal, LVMH. She was the Director of the Faurecia Manufacturing \& Logistics Chair. She has supervised 15 Ph.D. theses in operations management and is currently supervising $4 \mathrm{Ph} . \mathrm{D}$. doctorates. She has been the author or co-author of more than 100 papers with review committee, including 40 journal papers. She currently sits on the Editorial Board of the Flexible Service and Manufacturing Journal. She is serving as expert nominated the French Ministry of Research for quality evaluation of research institutions and educational curricula in her domain. In education, she is head of the last year engineering program on Supply Chain and Operations Management of CentraleSupelec.

Nico J. Vandaele holds a degree in Business Engineering and obtained a PhD in Applied Economics, Operations Research and Operations Management from KU Leuven in 1996. As full professor at KU Leuven, he is holder of the GSK Research Chair on Access-to-Medicines and leads the Access-to-Medicines Research Center. Nico Vandaele teaches courses in operations research, operations management and supply chain management. He is intensively involved in health system design, with current focus on immunization, HIV and neglected tropical diseases in a Sub-Sahara context, in collaboration with various international organizations. His other research interests are situated in supply chain design, modeling of manufacturing and service systems, the design of planning systems, sales and operations management, health care management and traffic modeling. Another research area deals with decision support systems for product design and development and (R\&D) portfolio management. He is associate editor of Flexible 
Services and Manufacturing Journal, published in multiple OR/MS and OM journals, is co-founder of the Health Care Systems Engineering conference and is board member of the EURO WG on Humanitarian Operations and the WG on Stochastic Modeling.

Filippo Visintin is an Associate Professor of Service Management and Design at the Department of Industrial Engineering of the University of Florence. He is the Scientific Director of the IBIS Lab and he is co-founder and co-owner of Smart Operations Srl (www.smartoperations.it). His research interests include servitization of manufacturing, circular economy, and health care operations management. He is heavily involved in health service design and improvement projects in collaboration with private and public health care providers. He is author of several research papers published in journals such as European Journal of Operational Research, Industrial Marketing Management, International Journal of Production Economics, Computers and Industrial Engineering, Computers in Industry, Flexible Service and Manufacturing Journal, Journal of Intelligent Manufacturing, Production Planning and Control, Management Decision and IMA Journal of Management Mathematics. He has served as guest editor for Flexible Service and Manufacturing Journal and Management Decision. 